Ernst-Wilhelm Radue, MD*

Till Sprenger, MD*

Laura Gaetano, PhD

Nicole Mueller-Lenke, MD

Steve Cavalier, MD

Karthinathan Thangavelu, PhD

Michael A. Panzara, MD

Jessica E. Donaldson,

$\mathrm{PhD}$

Fiona M. Woodward, $\mathrm{PhD}$

Jens Wuerfel, MD

Jerry S. Wolinsky, MD

Ludwig Kappos, MD

Correspondence to

Dr. Sprenger:

Till.Sprenger@helios-kliniken.de

or Dr. Wuerfel:

ceo-office@miac.ch
Supplemental data at Neurology.org/nn

\section{Teriflunomide slows BVL in relapsing MS}

\section{A reanalysis of the TEMSO MRI data set using SIENA}

OPEN

\section{ABSTRACT}

Objective: To assess, using structural image evaluation using normalization of atrophy (SIENA), the effect of teriflunomide, a once-daily oral immunomodulator, on brain volume loss (BVL) in patients with relapsing forms of MS enrolled in the phase 3 TEMSO study.

Methods: TEMSO MR scans were analyzed (study personnel masked to treatment allocation) using SIENA to assess brain volume changes between baseline and years 1 and 2 in patients treated with placebo or teriflunomide. Treatment group comparisons were made via rank analysis of covariance.

Results: Data from 969 patient MRI visits were included in this analysis: 808 patients had baseline and year $1 \mathrm{MRI} 709$ patients had baseline and year $2 \mathrm{MRI}$. Median percentage BVL from baseline to year 1 and year 2 for placebo was $0.61 \%$ and $1.29 \%$, respectively, and for teriflunomide $14 \mathrm{mg}, 0.39 \%$ and $0.90 \%$, respectively. BVL was lower for teriflunomide $14 \mathrm{mg}$ vs placebo at year 1 (36.9\% relative reduction, $p=0.0001$ ) and year $2(30.6 \%$ relative reduction, $p=$ $0.0001)$. Teriflunomide $7 \mathrm{mg}$ was also associated with significant reduction in BVL vs placebo over the 2-year study. The significant effects of teriflunomide $14 \mathrm{mg}$ on BVL were observed in both patients with and without on-study disability worsening.

Conclusions: The significant reduction of BVL vs placebo over 2 years achieved with teriflunomide is consistent with its effects on delaying disability worsening and suggests a neuroprotective potential.

Classification of evidence: Class II evidence shows that teriflunomide treatment significantly reduces BVL over 2 years vs placebo.

ClinicalTrials.gov identifier: NCT00134563. Neurol Neuroimmunol Neuroinflamm 2017;4:e390; doi: $10.1212 / \mathrm{NXI} .0000000000000390$

\section{GLOSSARY}

BPF $=$ brain parenchymal fraction; $\mathbf{B V L}=$ brain volume loss; CDW $=$ confirmed disability worsening; $\mathbf{D M T}=$ diseasemodifying therapy; $\mathbf{E A E}=$ experimental autoimmune encephalitis; EDSS = Expanded Disability Status Scale; MRIAP = MRI analysis package; SIENA = structural image evaluation using normalization of atrophy; SIENAX = SIENA crosssectional method.

Accelerated brain volume loss (BVL) starts in the early stages of MS and is associated with accumulating physical and cognitive disability. ${ }^{1-5}$ In a recent meta-analysis of clinical trials including patients with relapsing-remitting MS, treatment effects of disease-modifying therapies (DMTs) on BVL showed a strong correlation with treatment effects on disability worsening over 2 years. $^{6}$

In 2 phase 3 pivotal trials (TEMSO, NCT00134563, and TOWER, NCT00751881), teriflunomide 14 mg (AUBAGIO, Genzyme, Cambridge, MA), a once-daily oral immunomodulator approved for relapsing-remitting $\mathrm{MS}{ }^{7-9}$ significantly reduced the risk of 12 -week

\footnotetext{
*These authors contributed equally to the analysis.

From the Medical Image Analysis Center (MIAC AG) (E.-W.R., L.G., N.M.-L., J.W.), Basel, Switzerland; DKD HELIOS Klinik (T.S.),

Wiesbaden, Germany; Neurologic Clinic and Policlinic (T.S., L.G., L.K.), University Hospital Basel and University of Basel, Switzerland; Sanofi Genzyme (S.C., K.T.), Previously Sanofi Genzyme (M.A.P.), and WAVE Life Sciences (M.A.P.), Cambridge, MA; Fishawack Communications Ltd (J.E.D., F.M.W.), Abingdon, Oxfordshire, UK; and McGovern Medical School (J.S.W.), UTHealth, Houston, TX.

Funding information and disclosures are provided at the end of the article. Go to Neurology.org/nn for full disclosure forms. The Article Processing Charge was funded by Sanofi Genzyme.

This is an open access article distributed under the terms of the Creative Commons Attribution-NonCommercial-NoDerivatives License 4.0 (CC BY-NC-ND), which permits downloading and sharing the work provided it is properly cited. The work cannot be changed in any way or used commercially without permission from the journal.
} 
confirmed disability worsening (CDW) in patients with relapsing $\mathrm{MS}{ }^{10,11}$ A significant reduction in annualized relapse rate in both studies and a reduction in MRI activity in TEMSO were also reported (no MRI was performed in TOWER) ${ }^{10-12}$ BVL was assessed in TEMSO by changes in brain parenchymal fraction (BPF) using an MRI analysis package (MRIAP), developed and performed at UTHealth, Houston, TX. The results demonstrated numerical reduction of BVL by $\sim 25 \%$ with teriflunomide $14 \mathrm{mg}$ vs placebo, but this was not statistically significant. ${ }^{12}$ The MRIAP method has had limited use in successful large phase 3 studies in MS; therefore, it is difficult to assess its sensitivity for detecting change and therapeutic effects across different DMTs. Structural image evaluation using normalization of atrophy (SIENA) is a well-established, longitudinal, registration-based technique with a low error rate in detecting brain volume changes over time. ${ }^{13,14}$

Given the consistent and statistically significant effects of teriflunomide on reducing the risk of disability worsening, and the strong association between BVL and disability worsening in MS, a new masked analysis of TEMSO MRI was undertaken using SIENA.

METHODS Standard protocol approvals, registrations, and patient consents. The TEMSO study (ClinicalTrials.gov identifier NCT00134563) was conducted in accordance with the International Conference on Harmonisation Guidelines for Good Clinical Practice and the Declaration of Helsinki. The protocol was approved by central and local ethics committees and the respective institutional review board; patients provided written informed consent before entering the study.

Study design. TEMSO was a 2-year, phase 3, randomized, double-blind, placebo-controlled, parallel-group study designed to evaluate the efficacy and safety of teriflunomide in reducing the frequency of relapses and progression of physical disability in patients who had relapsing MS, as reported previously. ${ }^{10}$ After a screening phase of up to 4 weeks, eligible patients were randomly assigned (in a 1:1:1 ratio) to receive a once-daily oral dose of placebo, $7 \mathrm{mg}$ of teriflunomide, or $14 \mathrm{mg}$ of teriflunomide for 108 weeks.

The primary objective of the SIENA reanalysis of the TEMSO MRI data set was to evaluate the effect of teriflunomide vs placebo on BVL from baseline to year 1 and year 2 .

MRI analysis. MR scans collected from the TEMSO study ${ }^{12}$ at baseline and at weeks 48 (year 1) and 108 (year 2) were analyzed using the SIENA method, as performed at the Medical Image Analysis Center (MIAC AG, Basel, Switzerland). Further details of the specific SIENA methodology used for this analysis are provided in the supplementary material.

SIENA was applied to 3-mm thick precontrast T1-weighted images of a $70-\mathrm{mm}$ central brain area section (Montreal
Neurological Institute $Z$ coordinates -10 to $+60 \mathrm{~mm}$ ), which was selected for optimal reproducibility and comparability to previous trials of other oral DMTs. ${ }^{15-21}$ MR images of 2 time points were coregistered, and surface changes were determined using the fully automated algorithm to estimate brain volume changes (figure e-1 at Neurology.org/nn).

In addition, the single-point SIENA cross-sectional method $(\operatorname{SIENAX})^{13}$ was also applied to the T1-weighted images to estimate the normalized whole-brain volume of each patient at baseline (figure e-2).

Study personnel were masked to treatment allocation and other study data. A rigorous quality control of all uploaded MRI data and all stages of the SIENA analysis was performed. This led to the exclusion of some scans for 1 or more of the following reasons: required MRI sequence(s) for the evaluation were missing, quality of MRI sequence(s) was insufficient for the evaluation, and reference or longitudinal follow-up MRI was missing or excluded from the analysis for one of the aforementioned reasons.

Statistical analysis. The change from baseline in annualized percentage brain volume was analyzed, and median $(95 \% \mathrm{CI})$ values were determined for each treatment group. Treatment group comparisons were made via nonparametric analysis of covariance, adjusted for region, age, Expanded Disability Status Scale (EDSS) strata, and normalized brain volume (using SIENAX). A similar method was applied for treatment group comparisons in a subgroup analysis of BVL in patients with or without on-study $\mathrm{CDW}$, defined as an increase from baseline of at least 1.0 point in the EDSS score (or at least 0.5 points for patients with a baseline EDSS score greater than 5.5) that persisted for at least 12 or 24 weeks. The relationship between CDW and BVL was evaluated using a Cox model with CDW as the dependent variable and BVL as the independent variable, together with other covariates (treatment and stratification factors used for randomization). As this SIENA analysis was a masked reanalysis, but not a prospectively defined analysis as per the TEMSO protocol, no formal adjustment for multiplicity was performed.

Classification of evidence. This study provides Class II evidence of reduction in BVL, as assessed by masked SIENA analysis, over 2 years of treatment with once-daily oral teriflunomide $7 \mathrm{mg}$ or $14 \mathrm{mg}$, compared with placebo, in patients with relapsing forms of MS.

RESULTS Patients. At each time point, $\geq 89.5 \%$ of the patient scans included in the original MRI analysis of the TEMSO study (described as the TEMSO MRI population below) were deemed suitable for inclusion at the corresponding time point in the SIENA analysis: 969 patients had baseline MRI; 808 had baseline and year 1 MRI (scans from 95/903 patients [10.5\%] with evaluable MRI in the TEMSO MRI population, were excluded at year 1 , before SIENA analysis); and 709 had baseline and year 2 MRI (scans from $69 / 778$ patients [8.9\%] were excluded at year 2). The mean (SD) normalized brain volume values at baseline for those patients included in the SIENA analysis were similar between the 3 treatment groups: $1,508.9 \mathrm{~cm}^{3}\left(77.9 \mathrm{~cm}^{3}\right), 1,507.8 \mathrm{~cm}^{3}\left(83.1 \mathrm{~cm}^{3}\right)$, and $1,502.7 \mathrm{~cm}^{3}\left(75.8 \mathrm{~cm}^{3}\right)$, for placebo and teriflunomide 7 and $14 \mathrm{mg}$, respectively ( $p=0.5610$; for the comparison between groups of baseline normalized brain volume). 


\begin{tabular}{|c|c|c|}
\hline \multirow[t]{2}{*}{ Patient demographics and } & eline clinical character & \\
\hline & $\begin{array}{l}\text { TEMSO MRI population } \\
(\mathrm{N}=903)\end{array}$ & $\begin{array}{l}\text { SIENA analysis } \\
(\mathrm{N}=808)\end{array}$ \\
\hline Age, mean (SD), y & $37.9(8.7)$ & $37.8(8.7)$ \\
\hline Female, n (\%) & 653 (72.3) & 602 (74.5) \\
\hline Time since first diagnosis, mean (SD), y & $5.29(5.42)$ & $5.26(5.51)$ \\
\hline \multicolumn{3}{|l|}{ Number of relapses, mean (SD) } \\
\hline Within past 1 year & $1.4(0.7)$ & $1.4(0.7)$ \\
\hline Within past 2 years & $2.2(1.0)$ & $2.2(1.0)$ \\
\hline Baseline EDSS score, mean (SD) & $2.61(1.29)$ & 2.59 (1.29) \\
\hline MS treatment in previous 2 years, $n$ (\%) & $236(26.1)$ & $208(25.7)$ \\
\hline $\begin{array}{l}\text { Baseline brain parenchymal fraction, } \\
\text { mean (SD) }\end{array}$ & $0.76(0.024)$ & $0.76(0.024)$ \\
\hline
\end{tabular}

Abbreviations: EDSS = Expanded Disability Status Scale; SIENA = structural image evaluation using normalization of atrophy.

${ }^{a}$ Demographics shown for patients with a baseline and year 1 scan; similar data were seen for patients with a baseline and year 2 scan, as well as patients with MRI of sufficient quality at all time points.

${ }^{\mathrm{b}}$ From original TEMSO analysis. between the groups analyzed: those to be included in the new SIENA analysis only, those included in the original TEMSO MRI population only, and those excluded from the new SIENA analysis (figure e-3).

Relationship between on-study disability worsening and BVL. In a Cox model, BVL over 2 years had an effect on CDW: risk reduction of $11 \%$ for every $1 \%$ change in brain volume ( $p=0.0203)$.

The normalized brain volume at baseline was lower in the patient subgroup with subsequent onstudy disability worsening vs the subgroup without disability worsening. At baseline, patients with and without 12-week CDW had mean (SD) brain volumes of $1,495 \mathrm{~cm}^{3}\left(83.4 \mathrm{~cm}^{3}\right)$ and $1,509 \mathrm{~cm}^{3}$ $\left(77.6 \mathrm{~cm}^{3}\right)$, respectively; $p=0.02$. Patients with and without 24-week CDW had brain volumes of $1,493 \mathrm{~cm}^{3}\left(86.7 \mathrm{~cm}^{3}\right)$ and $1,509 \mathrm{~cm}^{3}\left(77.5 \mathrm{~cm}^{3}\right)$, respectively; $p=0.03$.

Placebo-treated patients demonstrated increased rates of BVL if they also had on-study disability worsening vs those without worsening (figure 2A). Of note, BVL remained statistically significantly lower in patients treated with teriflunomide $14 \mathrm{mg}$ than in placebo-treated patients, regardless of the presence or absence of on-study disability worsening at both years 1 and 2 (figure 2, B and C). The median percentage change from baseline in patients treated with teriflunomide $14 \mathrm{mg}$ with vs without on-study 12 -week CDW at year 1 was -0.25 vs $-0.40(p=$ 0.48 ), respectively, and at year 2 was -0.90 vs -0.87 ( $p=0.68)$, respectively.

A similar pattern of reduced BVL was observed in patients receiving teriflunomide $7 \mathrm{mg}$, although results did not reach statistical significance in the subgroup of patients without 12- or 24-week CDW from baseline to year 2 (figure e-4, A and B).

DISCUSSION Limiting BVL in MS is increasingly recognized as an evolving and important therapeutic goal, despite challenges of measurement at an individual patient level. The importance of BVL is due, in part, to the recognized association between BVL and long-term accumulation of physical and cognitive disability, which reduce both patients' functional ability and their quality of life. Accelerated BVL can be evident from the earliest stages of MS, which highlights the need for early and effective intervention. ${ }^{1,22,23}$ In this masked reanalysis of the TEMSO MRI data set using the SIENA method, teriflunomide significantly slowed BVL vs placebo, an effect that was maintained to the end of the TEMSO core study.

SIENA is a well-established longitudinal registrationbased technique with a low error rate in detecting brain 
A

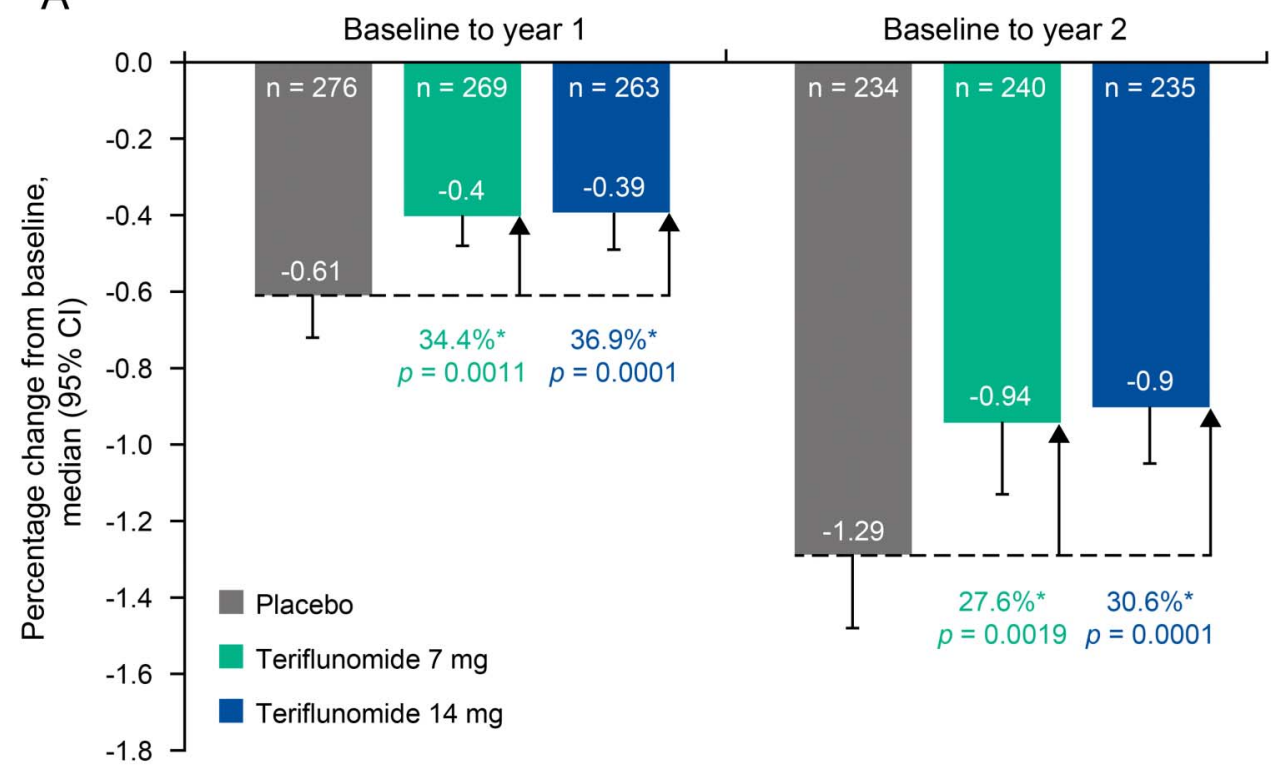

B

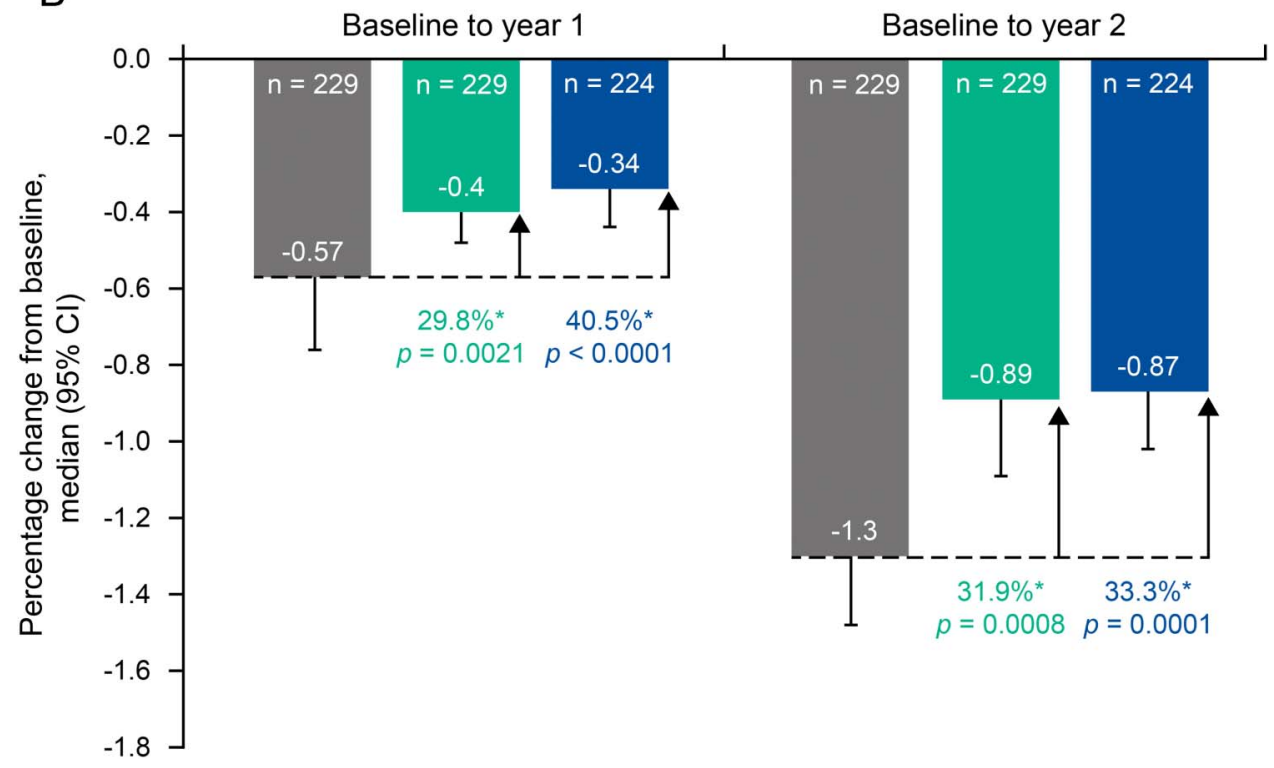

Annualized median percentage change from baseline in BVL over 2 years for teriflunomide 14 and $7 \mathrm{mg}$ vs placebo: (A) using all scans available at each time point; (B) for patients with complete scan series at all time points. BVL = brain volume loss; $\mathrm{Cl}=$ confidence interval; *Relative change vs placebo.

volume changes over time ${ }^{13,14}$ and has been repeatedly used to measure treatment effects on brain atrophy with oral DMTs other than teriflunomide. ${ }^{15-21}$ SIENA can outperform many cross-sectional methods regarding sensitivity and reproducibility ${ }^{13,24}$ and, thus, may be better suited for this purpose. ${ }^{12}$

This analysis of TEMSO MRI using the SIENA methodology was conducted using the same procedures as in other phase 3 studies of oral DMTs, ${ }^{15-21}$ with study personnel masked to treatment allocation and other study data. By applying rigorous qualitycontrol criteria, some TEMSO MRIs were excluded in this reanalysis. It is acknowledged that exclusion of scans as a result of rigorous quality-control has the potential to introduce selection bias. Nonetheless, a sensitivity analysis demonstrated that exclusion of some TEMSO MRI did not affect baseline or other characteristics of the patients assessed.

The significant reduction in BVL observed in this analysis is consistent with the positive effect of teriflunomide on disability worsening already initially observed in a phase 2 study and later confirmed in both phase 3 studies: TEMSO and TOWER, which compared teriflunomide with placebo in patients with 
A. Confirmed disability worsening

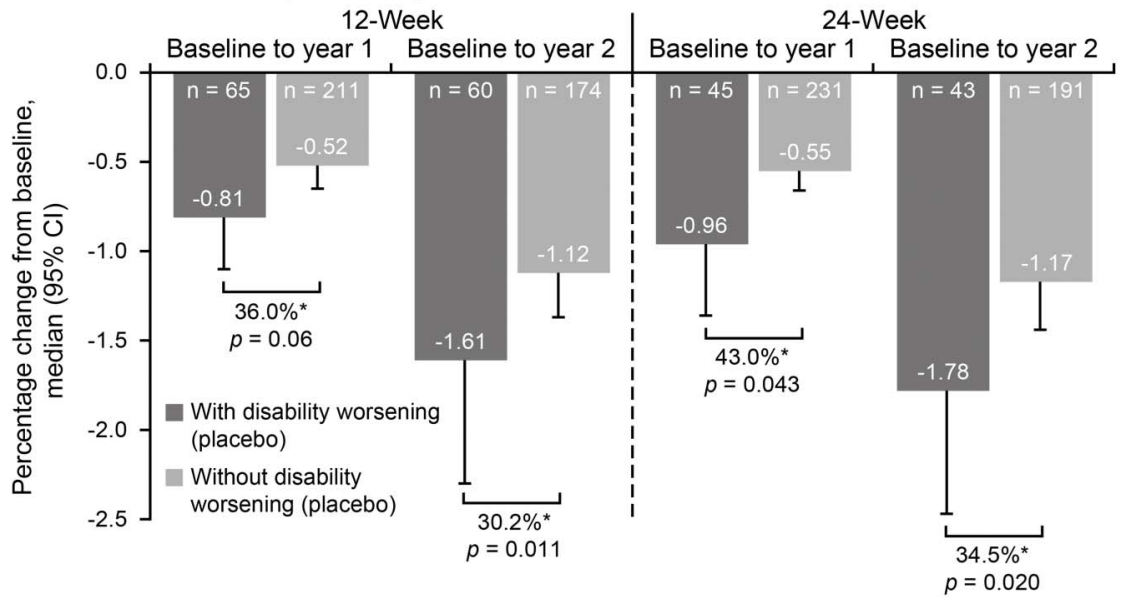

B. With confirmed disability worsening

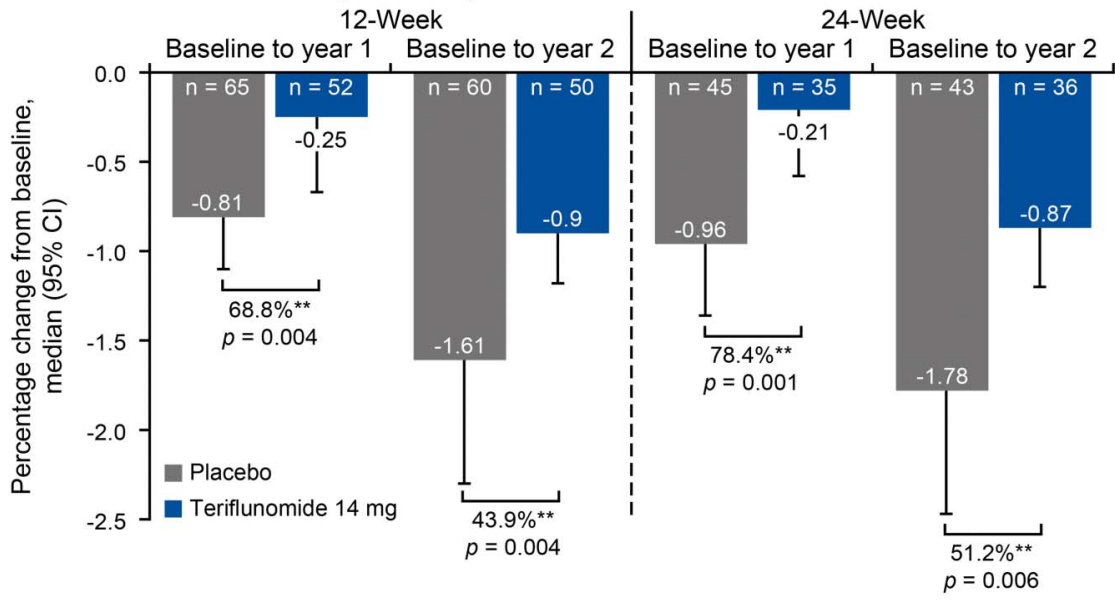

C. Without confirmed disability worsening

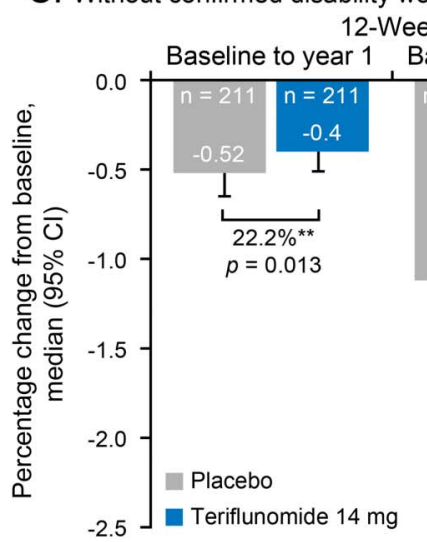

24-Week

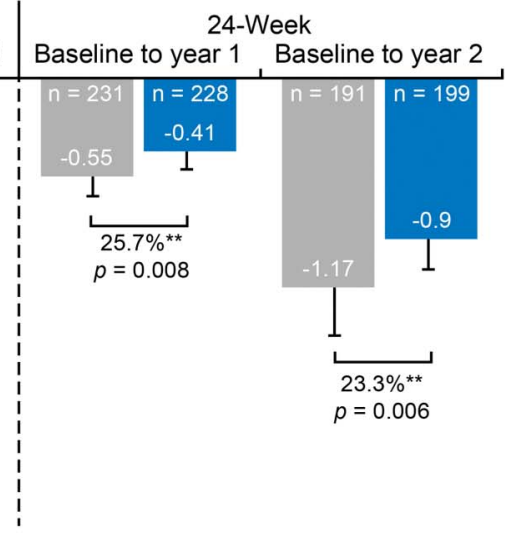

BVL according to on-study disability worsening in (A) placebo-treated patients with and without 12- or 24-week confirmed disability worsening (CDW); (B) placebo- and teriflunomide 14 mg-treated patients with 12- or 24-week CDW; (C) placeboand teriflunomide $14 \mathrm{mg}$-treated patients without 12- or 24-week CDW. BVL = brain volume loss; $\mathrm{Cl}$ = confidence interval. *Relative change vs patients without CDW; **Relative change vs placebo.

relapsing forms of MS. ${ }^{10,11,25}$ Our additional analysis showing faster rates of BVL in placebo-treated patients with on-study disability worsening compared with those without worsening provides further evidence that greater BVL is related to an increased risk of disability worsening. On-study disability worsening may also reflect the clinical manifestations of accumulated BVL before the start of the TEMSO study, as evidenced by lower baseline brain volumes in the subgroup with disability worsening vs the 
subgroup without. Nevertheless, treatment with teriflunomide was associated with a significant reduction in BVL, regardless of the presence of on-study disability worsening, suggesting that teriflunomide exerts this effect in a broad range of patients with MS.

In a meta-analysis of data from 13 randomized clinical trials evaluating DMTs in patients with RRMS, the size of the treatment effect on brain atrophy was closely correlated with the size of treatment effect on 2-year disability worsening at the trial level $\left(R^{2}=0.48\right){ }^{6}$ The meta-analysis included the data from the original MRIAP analysis of BPF changes conducted in TEMSO. ${ }^{12}$ When the 13-trial meta-analysis was repeated, replacing the MRIAP analysis of TEMSO MRI with the SIENA analysis of BVL, the $R^{2}$ values for the treatment effect correlation between brain atrophy and disability worsening strengthened from 0.48 to $0.61 .^{26}$

Preservation of brain volume with teriflunomide is consistent with its proposed mechanism of action in MS. The primary mechanism of action of teriflunomide is believed to relate to the reversible inhibition of proliferation of activated $\mathrm{T}$ and $\mathrm{B}$ lymphocytes, thereby limiting their involvement in damaging processes within the CNS. ${ }^{27}$ Studies of teriflunomide administered to rats with experimental autoimmune encephalitis (EAE) at disease onset showed reduced lymphocyte counts in the rats' spinal cords. ${ }^{28} \mathrm{EAE}$ animals dosed therapeutically with teriflunomide showed reduced CNS inflammation, reduced disease scores, reduced axonal damage and demyelination, and preserved sensory and motor neuronal function compared with untreated EAE animals. ${ }^{29,30}$ However, whether these results are driven solely by the anti-inflammatory effects of the drug acting in the periphery is currently unclear. Evidence is emerging that teriflunomide is found in the CNS at pharmacologically relevant concentrations and that teriflunomide treatment in vitro has direct effects on activated rodent microglia and astrocyte functions, ${ }^{31}$ suggesting that teriflunomide may have potential neuroprotective effects within the CNS, at least in rodents.

In this new analysis, teriflunomide-an immunomodulatory DMT with established efficacy on annualized relapse rate, disability worsening, and MRI lesion activity-has been demonstrated to reduce BVL. This result-besides indicating a neuroprotective potential of teriflunomide-further strengthens the evidence of a link between BVL and disability worsening.

\section{AUTHOR CONTRIBUTIONS}

E.-W. Radue, T. Sprenger, L. Gaetano, N. Mueller-Lenke, S. Cavalier, M.A. Panzara, J. Wuerfel, J.S. Wolinsky, and L. Kappos: design or conceptualization of the study and/or analysis or interpretation of the data. L. Gaetano and K. Thangavelu: analysis or interpretation of the data. E.-W. Radue, T. Sprenger, L. Gaetano, N. Mueller-Lenke, S. Cavalier, K. Thangavelu, M.A. Panzara, J.E. Donaldson, F.M. Woodward, J. Wuerfel, J.S. Wolinsky, and L. Kappos: drafting or revising the manuscript for intellectual content.

\section{ACKNOWLEDGMENT}

The authors acknowledge the contribution of the TEMSO study investigators, the members of UTHealth, Houston, TX, the central MRI center for the TEMSO Study, and Pascal Kuster and Stefan Traud of MIAC AG for their technical assistance and support in data preparation and processing pipeline handling. This manuscript was reviewed by Larisa Miller, PharmD, of Sanofi Genzyme. Drafting and editorial support for this manuscript were provided by Jessica Donaldson and Fiona Woodward, of Fishawack Communications Ltd. (Abingdon, UK), and was funded by Sanofi Genzyme.

\section{STUDY FUNDING}

Supported by Sanofi Genzyme.

\section{DISCLOSURE}

E.-W. Radue received speaker honoraria and travel compensation from Bayer Schering, Biogen, Fondazione Italiana Sclerosi Multipla, Genzyme, Novartis, Merck Serono, MorphoSys, and Synthon; consulted for Bayer Schering, Biogen Idec, Fondazione Italiana Sclerosi Multipla, Genzyme, Novartis, Merck Serono, Synthon, and MorphoSys; and received institutional research support from Novartis, Biogen Idec, Actelion, Basilea, SAKK, and Synarc. T. Sprenger served on the scientific advisory board for Sanofi Genzyme, Novartis, Actelion, Electrocore, and Mitsubishi Pharma; received speaker honoraria from Biogen, Sanofi Genzyme, Teva, Novartis, and Desitin; and received research support from Novartis Pharma, EFIC-Grunenthal, Swiss National Science Foundation, and Swiss MS Society. L. Gaetano served on the scientific advisory board for Novartis Pharma AG and interned for Novartis Pharma AG. N. Mueller-Lenke reports no disclosures. S. Cavalier is employed by Sanofi Genzyme. K. Thangavelu is employed by Sanofi Genzyme. M.A. Panzara was previously employed by Sanofi Genzyme and is currently employed by WAVE Life Sciences. J.E. Donaldson is employed by Fishawack Communications Ltd. F.M. Woodward is employed by Fishawack Communications Ltd. J. Wuerfel served on the scientific advisory board for Novartis, Biogen, Genzyme, Teva, and Roche; received travel support and/or speaker honoraria from Bayer, Biogen, and Novartis; is employed by MIAC AG; and received research support from the German Ministry of Education and Research and the German Ministry of Economy. J.S. Wolinsky served on the scientific advisory board for AbbVie, Alkermes, Bayer Healthcare, Biogen, Bionest, Celgene, Clene Nanomedicine, EMD Serono, Forward Pharma A/S, MedDay, Novartis, Roche/Genentech, Sanofi/ Genzyme, Takeda, and Teva; received travel funding and/or speaker honoraria from Academic CME, ACTRIMS, CMSC, ECTRIMS, Masters MS, Medscape, PRIME, and WebMD; served on the editorial board for Multiple Sclerosis Journal and Multiple Sclerosis and Related Diseases; holds a patent for Methods for treating CNS Lesions; consulted for AbbVie, Alkermes, Bayer Healthcare, Biogen, Bionest, Celgene, Clene Nanomedicine, Forward Pharma A/S, EMD Serono, Novartis, Roche/ Genentech, Sanofi/Genzyme, Misspelt, and Teva; received research support from $\mathrm{NIH}$; and received royalties for monoclonal antibodies out-licensed through the University of Texas Health Science Center at Houston to Millipore. L. Kappos served on the editorial board for Multiple Sclerosis Journal, Multiple Sclerosis and Related Disorders, and Journal of Neurology; received research support from Actelion, Alkermes, Almirall, Bayer, Biogen, Excemed, GeNeuro SA, Genzyme, Merck, Mitsubishi Pharma, Novartis, Receptos, Roche, Sanofi-Aventis, Santhera, Teva, Vianex, the Swiss MS Society, the Swiss National Research Foundation, the European Union, and Roche Research Foundations; and receives license fees for Neurostatus products paid directly to University Hospital Basel. Go to Neurology.org/nn for full disclosure forms.

Received March 3, 2017. Accepted in final form June 27, 2017. 


\section{REFERENCES}

1. De Stefano N, Airas L, Grigoriadis N, et al. Clinical relevance of brain volume measures in multiple sclerosis. CNS Drugs 2014;28:147-156.

2. Riley C, Azevedo C, Bailey M, Pelletier D. Clinical applications of imaging disease burden in multiple sclerosis: MRI and advanced imaging techniques. Expert Rev Neurother 2012;12:323-333.

3. Popescu V, Agosta F, Hulst HE, et al. Brain atrophy and lesion load predict long term disability in multiple sclerosis. J Neurol Neurosurg Psychiatry 2013;84:1082-1091.

4. Calabrese M, Agosta F, Rinaldi F, et al. Cortical lesions and atrophy associated with cognitive impairment in relapsing-remitting multiple sclerosis. Arch Neurol 2009; 66:1144-1150.

5. Marcus JF, Waubant EL. Updates on clinically isolated syndrome and diagnostic criteria for multiple sclerosis. Neurohospitalist 2013;3:65-80.

6. Sormani MP, Arnold DL, De Stefano N. Treatment effect on brain atrophy correlates with treatment effect on disability in multiple sclerosis. Ann Neurol 2014;75:43-49.

7. Genzyme. AUBAGIO (Summary of Product Characteristics). Available at: ema.europa.eu/docs/en_GB/ document_library/EPAR___Product_Information/human/ 002514/WC500148682.pdf. Accessed December 5, 2016.

8. Genzyme. AUBAGIO (Package Insert). Available at: accessdata.fda.gov/drugsatfda_docs/label/2016/202992s002 lbl.pdf. Accessed December 8, 2016.

9. Bar-Or A, Pachner A, Menguy-Vacheron F, Kaplan J, Wiendl $\mathrm{H}$. Teriflunomide and its mechanism of action in multiple sclerosis. Drugs 2014;74:659-674.

10. O'Connor P, Wolinsky JS, Confavreux C, et al. Randomized trial of oral teriflunomide for relapsing multiple sclerosis. N Engl J Med 2011;365:1293-1303.

11. Confavreux C, O'Connor P, Comi G, et al. Oral teriflunomide for patients with relapsing multiple sclerosis (TOWER): a randomised, double-blind, placebo-controlled, phase 3 trial. Lancet Neurol 2014;13:247-256.

12. Wolinsky JS, Narayana PA, Nelson F, et al. Magnetic resonance imaging outcomes from a phase III trial of teriflunomide. Mult Scler 2013;19:1310-1319.

13. Smith SM, Zhang Y, Jenkinson M, et al. Accurate, robust, and automated longitudinal and cross-sectional brain change analysis. Neuroimage 2002;17:479-489.

14. Smith SM, Zhang Y, Jenkinson M, et al. TR01SMS1: Brain Atrophy Analysis Using Single- and MultipleTime-Point Data. FMRIB Technical Note. 2001. Available at: fmrib.ox.ac.uk/datasets/techrep/tr01ss1/tr01ss1. pdf. Accessed February 3, 2017.

15. Kappos L, Radue EW, O'Connor P, et al. A placebocontrolled trial of oral fingolimod in relapsing multiple sclerosis. N Engl J Med 2010;362:387-401.

16. Calabresi PA, Radue EW, Goodin D, et al. Safety and efficacy of fingolimod in patients with relapsing-remitting multiple sclerosis (FREEDOMS II): a double-blind, randomised, placebo-controlled, phase 3 trial. Lancet Neurol 2014;13:545-556.

17. Radue EW, Goodin D, Jeffery D, et al. Fingolimod reduces magnetic resonance imaging inflammatory lesion activity versus placebo in patients with relapsing- remitting multiple sclerosis: results from the phase 3 FREEDOMS II study. Presented at the 28th Congress of the European Committee for Treatment and Research in Multiple Sclerosis; October 10-13, 2012; Lyon, France.

18. Arnold DL, Gold R, Kappos L, et al. Effects of delayedrelease dimethyl fumarate on MRI measures in the Phase 3 DEFINE study. J Neurol 2014;261:1794-1802.

19. Gold R, Kappos L, Arnold DL, et al. Placebo-controlled phase 3 study of oral BG-12 for relapsing multiple sclerosis. N Engl J Med 2012;367:1098-1107.

20. Fox RJ, Miller DH, Phillips JT, et al. Placebo-controlled phase 3 study of oral BG-12 or glatiramer in multiple sclerosis. N Engl J Med 2012;367:1087-1097.

21. Miller DH, Fox RJ, Phillips JT, et al. Effects of delayedrelease dimethyl fumarate on MRI measures in the phase 3 CONFIRM study. Neurology 2015;84:1145-1152.

22. Radue EW, Barkhof F, Kappos L, et al. Correlation between brain volume loss and clinical and MRI outcomes in multiple sclerosis. Neurology 2015;84:784-793.

23. Mowry EM, Beheshtian A, Waubant E, et al. Quality of life in multiple sclerosis is associated with lesion burden and brain volume measures. Neurology 2009; 72:1760-1765.

24. Durand-Dubief F, Belaroussi B, Armspach JP, et al. Reliability of longitudinal brain volume loss measurements between 2 sites in patients with multiple sclerosis: comparison of 7 quantification techniques. AJNR Am J Neuroradiol 2012;33:1918-1924.

25. Vidal-Jordana A, Sastre-Garriga J, Rovira A, Montalban X. Treating relapsing-remitting multiple sclerosis: therapy effects on brain atrophy. J Neurol 2015;262:2617-2626.

26. Sormani MP, Radue EW, Sprenger T, et al. Incorporating the TEMSO SIENA analysis improves correlation of brain atrophy and disability progression. Presented at the 2nd Congress of the European Academy of Neurology; May 28-31, 2016; Copenhagen, Denmark.

27. Li L, Liu J, Delohery T, Zhang D, Arendt C, Jones C. The effects of teriflunomide on lymphocyte subpopulations in human peripheral blood mononuclear cells in vitro. J Neuroimmunol 2013;265:82-90.

28. Ringheim GE, Lee L, Laws-Ricker L, et al. Teriflunomide attenuates immunopathological changes in the dark agouti rat model of experimental autoimmune encephalomyelitis. Front Neurol 2013;4:169.

29. Merrill JE, Hanak S, Pu SF, et al. Teriflunomide reduces behavioral, electrophysiological, and histopathological deficits in the dark Agouti rat model of experimental autoimmune encephalomyelitis. J Neurol 2009;256: 89-103.

30. Iglesias-Bregna D, Hanak S, Ji Z, et al. Effects of prophylactic and therapeutic teriflunomide in transcranial magnetic stimulation-induced motor-evoked potentials in the dark agouti rat model of experimental autoimmune encephalomyelitis. J Pharmacol Exp Ther 2013; 347:203-211.

31. Edling E, Woodworth L, Agrawal R, et al. Teriflunomide impacts primary microglia and astrocyte functions in vitro. 32nd Congress of the European Committee for Treatment and Research in Multiple Sclerosis; September 14-17, 2016; London, UK. 


\section{Neurology ${ }^{\oplus}$ \\ Neuroimmunology \& Neuroinflammation}

Teriflunomide slows BVL in relapsing MS: A reanalysis of the TEMSO MRI data set using SIENA

Ernst-Wilhelm Radue, Till Sprenger, Laura Gaetano, et al.

Neurol Neuroimmunol Neuroinflamm 2017;4;

DOI 10.1212/NXI.0000000000000390

This information is current as of August 9, 2017

Neurol Neuroimmunol Neuroinflamm is an official journal of the American Academy of Neurology.

Published since April 2014, it is an open-access, online-only, continuous publication journal. Copyright

Copyright (C) 2017 The Author(s). Published by Wolters Kluwer Health, Inc. on behalf of the American

Academy of Neurology. All rights reserved. Online ISSN: 2332-7812.

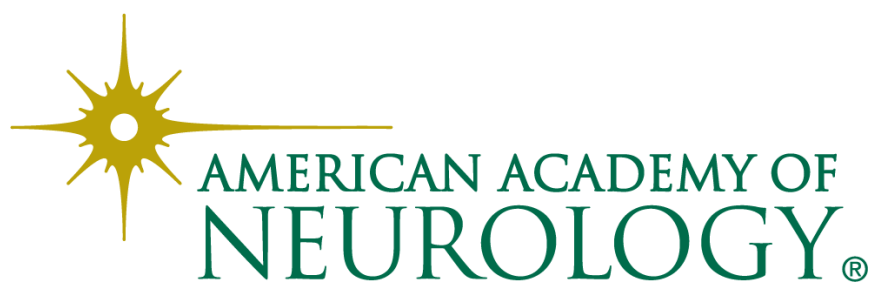




\section{Updated Information \& Services}

\section{Supplementary Material}

\section{References}

Citations

Subspecialty Collections

Permissions \& Licensing

\section{Reprints}

including high resolution figures, can be found at: http://nn.neurology.org/content/4/5/e390.full.html

Supplementary material can be found at: http://nn.neurology.org/content/suppl/2017/08/12/4.5.e390.DC1

This article cites 25 articles, 3 of which you can access for free at: http://nn.neurology.org/content/4/5/e390.full.html\#\#ref-list-1

This article has been cited by 2 HighWire-hosted articles: http://nn.neurology.org/content/4/5/e390.full.html\#\#otherarticles

This article, along with others on similar topics, appears in the following collection(s):

All Demyelinating disease (CNS)

http://nn.neurology.org//cgi/collection/all_demyelinating_disease_cns

\section{Class II}

http://nn.neurology.org//cgi/collection/class_ii

MRI

http://nn.neurology.org//cgi/collection/mri

Multiple sclerosis

http://nn.neurology.org//cgi/collection/multiple_sclerosis

Information about reproducing this article in parts (figures,tables) or in its entirety can be found online at:

http://nn.neurology.org/misc/about.xhtml\#permissions

Information about ordering reprints can be found online: http://nn.neurology.org/misc/addir.xhtml\#reprintsus

Neurol Neuroimmunol Neuroinflamm is an official journal of the American Academy of Neurology.

Published since April 2014, it is an open-access, online-only, continuous publication journal. Copyright

Copyright $\odot 2017$ The Author(s). Published by Wolters Kluwer Health, Inc. on behalf of the American Academy of Neurology. All rights reserved. Online ISSN: 2332-7812.

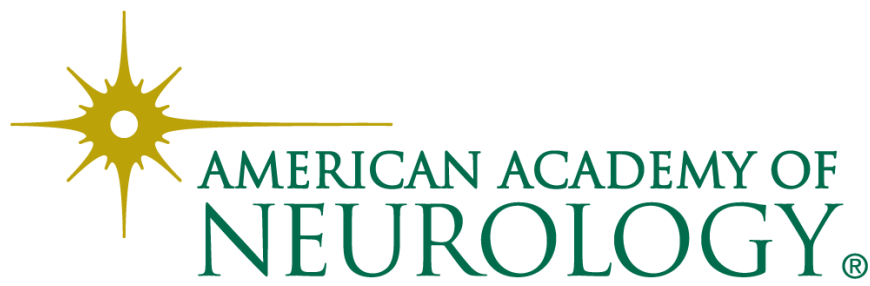

